University of Wollongong

Research Online

Australian Institute for Innovative Materials -

Papers

Australian Institute for Innovative Materials

$1-1-2013$

Evaluation of encapsulating coatings on the performance of polypyrrole actuators

Sina Naficy

University of Wollongong, snaficy@uow.edu.au

Nicholas Stoboi

University of Wollongong

Philip G. Whitten

University of Wollongong, whitten@uow.edu.au

Geoffrey M. Spinks

University of Wollongong, gspinks@uow.edu.au

Gordon G. Wallace

University of Wollongong, gwallace@uow.edu.au

Follow this and additional works at: https://ro.uow.edu.au/aiimpapers

Part of the Engineering Commons, and the Physical Sciences and Mathematics Commons

Research Online is the open access institutional repository for the University of Wollongong. For further information contact the UOW Library: research-pubs@uow.edu.au 


\title{
Evaluation of encapsulating coatings on the performance of polypyrrole actuators
}

\begin{abstract}
Conjugated polymer actuators are electroactive materials capable of generating force and movement in response to an applied external voltage. Many potential biomedical and industrial applications require these actuators to operate in a liquid environment. However, immersion of uncoated conducting polymer actuators in non-electrolyte liquids greatly reduces their operating lifetime. Here, we demonstrate the use of spray coating as an effective and simple method to encapsulate polypyrrole (PPy) tri-layer bending actuators. Poly(styrene-b-isobutylene-b-styrene) (SIBS) was used as an encapsulating, compliant spray coating on PPy actuators. A significant enhancement in actuator lifetime in both air and water was observed by encapsulating the actuators. The change in stiffness and reduction in bending amplitude for coatings of different thickness was studied. A simple beam mechanics model describes the experimental results and highlights the importance of coating compliance for actuator coatings. The model may be used to evaluate other possible encapsulating materials. 2013 IOP Publishing Ltd.
\end{abstract}

\section{Keywords}

performance, actuators, polypyrrole, coatings, evaluation, encapsulating

\section{Disciplines}

Engineering | Physical Sciences and Mathematics

\section{Publication Details}

Naficy, S., Stoboi, N., Whitten, P. G., Spinks, G. M. \& Wallace, G. G. (2013). Evaluation of encapsulating coatings on the performance of polypyrrole actuators. Smart Materials and Structures, 22 (7), 075005-1-075005-8. 


\title{
Evaluation of encapsulating coatings on the performance of polypyrrole actuators.
}

\author{
Sina Naficy, Nicolas Stoboi, Philip G. Whitten, Geoffrey M. Spinks* and Gordon G. Wallace \\ ARC Centre of Excellence in Electromaterials Science and Intelligent Polymer Research Institute, \\ University of Wollongong, Wollongong, NSW, 2522, Australia \\ Email: gspinks@uow.edu.au
}

\begin{abstract}
Conjugated polymer actuators are electroactive materials capable of generating force and movement in response to an applied external voltage. Many potential biomedical and industrial applications require these actuators to operate in a liquid environment. However, immersion of uncoated conducting polymer actuators in non-electrolyte liquids greatly reduces their operating lifetime. Here, we demonstrate the use of spray coating as an effective and simple method to encapsulate polypyrrole (PPy) tri-layer bending actuators. Poly(styrene-b-isobutylene-b-styrene) (SIBS) was used as an encapsulating, compliant spray coating on PPy actuators. A significant enhancement in actuator lifetime in both air and water was observed by encapsulating the actuators. The change in stiffness and reduction in bending amplitude for coatings of different thickness was studied. A simple beam mechanics model describes the experimental results and highlights the importance of coating compliance for actuator coatings. The model may be used to evaluate other possible encapsulating materials.
\end{abstract}




\section{Introduction}

The use of conducting polymer actuators to generate biomimetic movements for biomedical and industrial applications has been extensively reviewed [1,2]. Some of the features that make the conjugated polymer actuators attractive for these applications include a large actuation strain (up to 20 $\%$ ), high generated stress $(\sim 5 \mathrm{MPa}$ ), suitable mechanical properties (modulus $\sim 0.2-3 \mathrm{GPa}$, tensile strength $\sim 30-120 \mathrm{MPa})$, low operational voltage $(\sim 1 \mathrm{~V})$, and ease of fabrication [3].

Conducting polymer actuators are typically operated electrochemically and need an electrolyte to operate. Actuation of bi-layer conjugated polymers (conjugated polymer films on flexible electrodes) has been successfully demonstrated when fully immersed in different aqueous solutions $[4,5]$ as well as in blood plasma, urine, and cell culture medium [6]. On the other hand, dry state bending actuators, i.e. wet or plasticised bending actuators synthesized in an electrolyte but operating in air, were fabricated based on a tri-layer configuration in which two conjugated polymer films are laminated on either side of a polymer electrolyte film [7-10]. Possible applications of dry conjugated polymer actuators (with different configurations) in various biomedical devices such as steerable catheters $[11,12]$, robotic fish [13] and cochlear implants [14] were reported previously. Although the actuators were capable of operating in air for reasonable times, the performance deteriorated as soon as solvent evaporated from the system. The use of less volatile solvents (e.g. propylene carbonate) can extend the lifetime in air, but does not resolve the problem completely, especially in the case of microactuators where solvent evaporation takes place much faster. To address the adverse effect of solvent evaporation from the system, conjugated polymer actuators were manufactured using ionic liquids [15,16] or solid electrolytes [17]. The cyclic lifetime and stability of actuators enhanced significantly when an ionic liquid was used as the electrolyte compared to propylene carbonate based electrolytes [15] and operation in air of up to $10^{4}$ cycles $(1 \mathrm{~Hz})$ was demonstrated [16]. Although enhanced performance was achieved, the actuation remained slow as a result of limited ionic mobility in ionic liquids and solid polyelectrolytes compared to the less viscous liquid electrolytes. Very short operating lifetimes were achieved when these actuators were immersed in liquid (such as water) because of the loss of the electrolyte. Moreover, it is desirable to encapsulate actuators that are 
intended to be used in biomedical applications to ensure the safety of the procedure. As a result, finding a way to effectively seal actuators within a biocompatible material is crucial to broaden the biomedical application of actuators.

Previous studies have investigated encapsulating materials for conducting polymer actuators with limited success. Thin polyethylene film was firstly used to encapsulate polypyrrole (PPy) actuator films embedded within a doped agar gel as a solid electrolyte [18]. Linear actuation in air of such PPy actuators under a $2 \mathrm{MPa}$ applied stress was demonstrated, showing a considerable deterioration in actuation performance after a few cycles of actuation. In another study, Scotch tape and petroleum jelly were used for encapsulation of PPy tri-layer actuators operating in water [19]. It was found that the Scotch tape increased the stiffness of the actuators and resulted in a dramatic loss in tip displacement. On the other hand, while petroleum jelly applied to the outside of actuators did not show any undesirable effect on the stiffness of actuators, stable performance with no degradation was only observed within the first 10 min of operation when immersed in water. A slow reduction in oscillation amplitude was reported after this short period. Other alternatives of barrier coatings such as Opticlean, Teflon wax, and Teflon silicon lubricant were also investigated for their effectiveness in enhancing the lifetime of tri-layer PPy actuators in water [20]. In general, when is immersed in water, none of the painted coatings mentioned above could provide a sufficient barrier to prevent the leaching of electrolyte (i.e. propylene carbonate) out or the diffusion of water into the actuators.

In this paper, a simple technique to address the encapsulation problem of tri-layer actuators is presented. A simple spray coating was employed to apply poly(styrene- $b$-isobutylene- $b$-styrene) (SIBS) on tri-layer PPy actuators. SIBS is a tri-block copolymer where two end blocks are polystyrene (PS) and the middle block is polyisobutylene (PIB). The polymer is a biocompatible thermoplastic elastomer with FDA approval that is currently used commercially for biomedical applications [21]. At room temperature, PS remains below its glass transition temperature and forms glassy spherical domains within an elastomeric PIB matrix. PIB itself is an elastomer notable for low diffusion of small molecules [22]. Spray coating was chosen since it is a fast and simple technique to apply gel coatings with various thicknesses, and unlike dip coating there is no direct contact taking 
place between the substrate and the coating solution. Of note, the viscosity of the gel coating when it coats the actuator is sufficiently high to prevent flow of the polymer, whilst being sufficiently low to bond with itself to form a pore free coating prior to drying.

\section{Experimental}

A schematic representation of a PPy tri-layer actuator is shown in figure 1(a). In brief, PPy was electrochemically polymerized on both sides of a gold sputter coated poly(vinylidene fluoride) (PVDF) film (thickness $110 \mu \mathrm{m}$, average pore size $0.45 \mu \mathrm{m}$, Sigma-Aldrich). When wet in a $0.1 \mathrm{M}$ electrolyte solution of lithium trifluoromethanesulfonimide $\left(\mathrm{Li}^{+} \mathrm{TFSI}^{-}\right)(3 \mathrm{M}$ Co.) in propylene carbonate (Sigma-Aldrich), PVDF acts as an electrolyte reservoir for the electroactive PPy outer layers. To electrically connect the tri-layer actuators to a power source, small neodymium magnets (4 $\mathrm{mm}$ in diameter, $0.5 \mathrm{~mm}$ thick) with a gold coating were used. Before gold sputter coating the magnets, copper wires were attached to the magnets using silver paint (SPI Paint).

SIBS was kindly provided by Boston Scientific Corporation $\left(80000-130000 \mathrm{~g} \mathrm{~mol}^{-1}\right)$. The stability of SIBS in water and propylene carbonate was characterised. SIBS was hot pressed forming a $\sim 2 \mathrm{~mm}$ thick sheet. Dumb-bell-shaped test pieces were cut from the SIBS sheet with a shape of ISO 37 Type 2. The mass, length and thickness of the cut SIBS samples were measured in air and prior to immersion in water or propylene carbonate for 2 weeks. Following the immersion, the SIBS samples mass and dimension were measured again and then subjected to a tensile test (Instron).

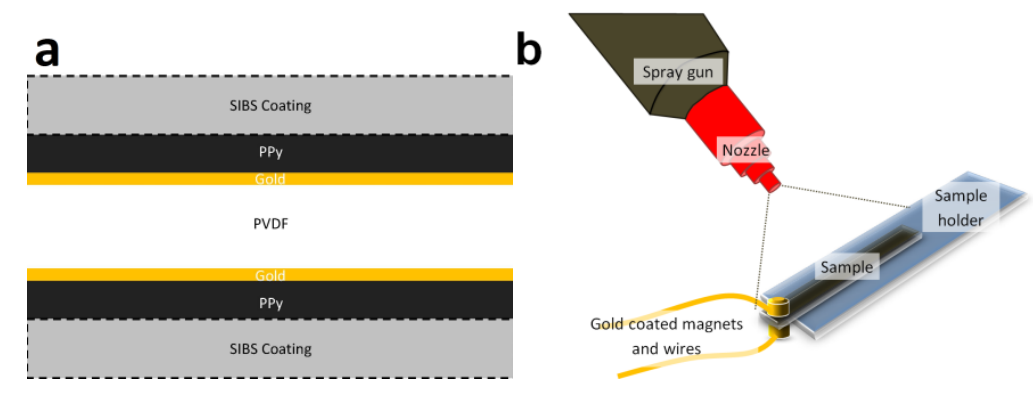


Figure 1. (a) Schematic representation of a tri-layer actuator with SIBS coating. (b) Experimental set up used for spray coating.

Various SIBS concentrations in toluene (Burdick \& Jackson) $(5,10$, and $15 \% \mathrm{w} / \mathrm{w})$ were used for spraying. A commercially available hand-held airbrush (Aztek A4709) was employed in a configuration shown in figure 1(b). A high flow nozzle designed for spraying lacquer was used. A pressure regulator was used to control the pressure of supplied compressed air fed to the airbrush. The angle and distance of spraying was kept constant for all experiments at, respectively, $90^{\circ}$, and 100 $\mathrm{mm}$. A simple stage was designed to hold samples during the spraying process. To optimize the spraying parameters, preliminary experiments were performed on $\mathrm{pH}$ strips followed by immersing the coated $\mathrm{pH}$ strips in a $10 \mathrm{mM} \mathrm{NaOH}$ solution. The coated $\mathrm{pH}$ strips were then visually examined for any colour change caused by $\mathrm{NaOH}$ penetration through the SIBS coating during the immersion. To resemble the wet tri-layer actuators, $\mathrm{pH}$ strips were fully immersed in propylene carbonate before spray coating. The quality of coating was investigated using the above technique to select the best spraying pattern that resulted in pinhole-free coatings. When sequential spraying was used, the nozzle tip was washed with toluene after each sequence of spraying to prevent clogging and undesirable SIBS fibrous strand formation.

Actuation of uncoated and coated tri-layer actuators was studied by generating a square wave voltage signal $(-1$ to $+1 \mathrm{~V})$ at $1 \mathrm{~Hz}$, using a function generator and a potentiostat (Princeton Applied Research) operating in two electrode mode. The voltage was applied to the actuators using the copper wires attached to the gold coated magnets. Actuator displacement was monitored using a laser displacement sensor (NCDT1700, Micro-Optronic) with $2.5 \mathrm{kHz}$ bandwidth, $10 \mathrm{~mm}$ measurement range and $0.5 \mu \mathrm{m}$ resolution. The laser sensor was connected to an e-corder data logger (ED 410, eDAQ) to convert voltage output to displacement. For each experiment voltage, current, and displacement were recorded using e-DAQ Chart software. Actuation was performed in air and immersed in water. The actuation set up is shown schematically in figure 2. 


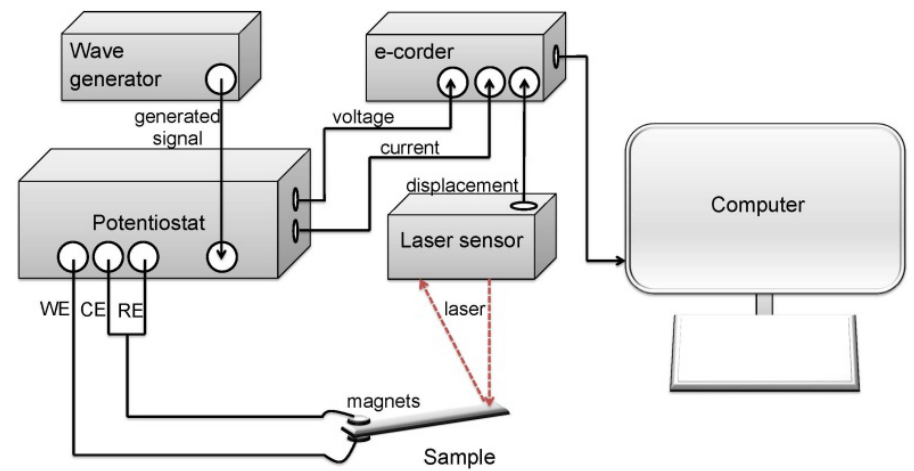

Figure 2. Schematic illustration of actuation experiment set up. WE: working electrode, CE: counter electrode, RE: reference electrode.

\section{Results and Discussions}

No changes to length or mass of dumb-bell-shaped SIBS samples were observed following immersion in water or propylene carbonate for 2 weeks. Within experimental variation, no changes to SIBS tensile properties were observed following immersion in water or propylene carbonate for 2 weeks (Supporting Information). Hence, it was determined that SIBS is stable in both water and the electrolyte used for tri-layer bending actuators reported here.

The effect of SIBS concentration was studied by spraying 5, 10 and $15 \% \mathrm{w} / \mathrm{w}$ SIBS in toluene using different nozzles. For the $5 \% \mathrm{w} / \mathrm{w}$ solution, a long total spraying time was required to achieve a suitable coating on the propylene carbonate-soaked $\mathrm{pH}$ strips with no visual colour change after immersing in $\mathrm{NaOH}$ solution. The $15 \% \mathrm{w} / \mathrm{w}$ solution did not produce consistent coatings with fibrous SIBS strands formed during the spraying process even when short spraying times (less than 10 seconds) were used. Since the $10 \% \mathrm{w} / \mathrm{w}$ SIBS solution resulted in reproducible good-quality coatings on propylene carbonate-soaked $\mathrm{pH}$ strips over short time periods, this concentration was selected for the remaining experiments. The measured mass flow rates were found to increase linearly with applied pressure for each nozzle. The nozzle with the highest flow rate and consistency was selected to undertake the rest of the experiments. 
In addition to the effect of SIBS concentration, pressure and nozzle type, the spraying pattern was also investigated to achieve adequate coatings. It was found that a sequential spraying routine in which spraying was performed on each side of the sample followed by drying time intervals to allow the solvent to evaporate could yield in high quality coatings. Thus, the selected spraying routine for the tri-layer actuators was as follows: first, an initial layer of SIBS was sprayed for 10 seconds on each side of the actuators with a 2 minute interval. Then, subsequent sprayings were applied for 3-5 seconds on each side of the actuators. The interval time between each spraying was 2 minutes. Coating thickness could be controlled by the number of spray applications used. From these preliminary experiments on $\mathrm{pH}$ strips it was found that a minimum of three sprayings on each side was required to produce a pinhole-free coating. SIBS solution was separately applied to the edges and the tip of the actuators using a $1 \mathrm{~mm}$ glass rod to transfer the solution onto the surface. The final spraying routine parameters used for tri-layer actuators are listed in table 1. Photographs of poly(pyrrole) tri-layer actuators before and after spray coating are shown in figure 3 along with crosssectional scanning electron micrographs of the SIBS spray coated actuators (JEOL, JSM7500FA). The coatings appeared to be dense with no apparent pin-holes in the coating layer.

Table 1. Spraying parameters used to produce coating on tri-layer actuators.

\begin{tabular}{cccccc}
\hline SIBS concentration & Pressure & Distance & Angle & Initial spray time & Sequential spray time \\
\hline $10 \% \mathrm{w} / \mathrm{w}$ & $20 \mathrm{psi}$ & $100 \mathrm{~mm}$ & $90^{\circ}$ & $10 \mathrm{sec}$ & $3-5 \mathrm{sec}$ \\
\hline
\end{tabular}

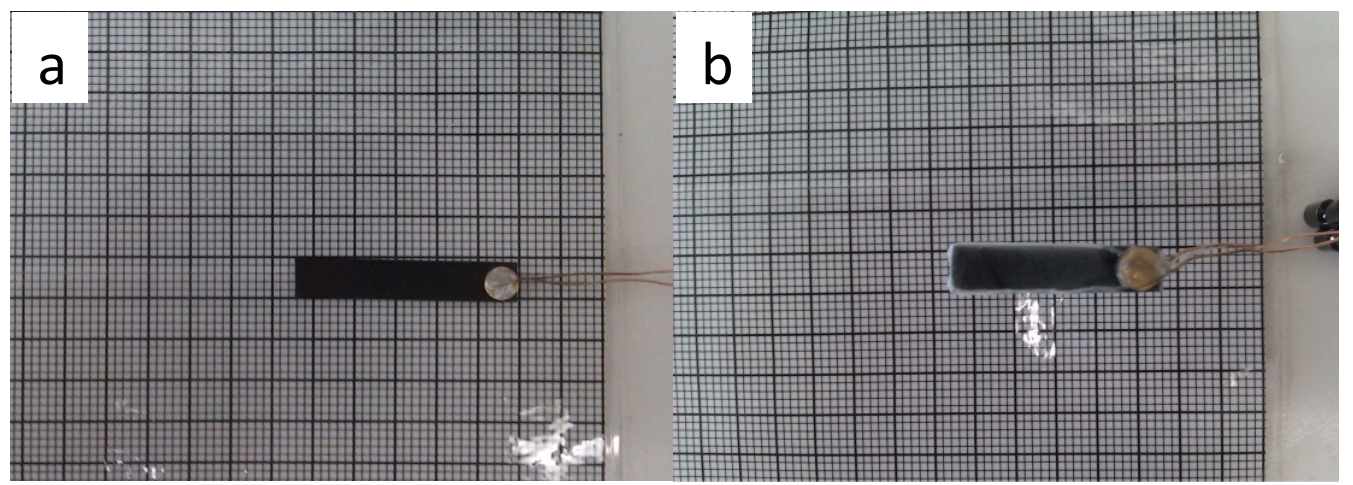




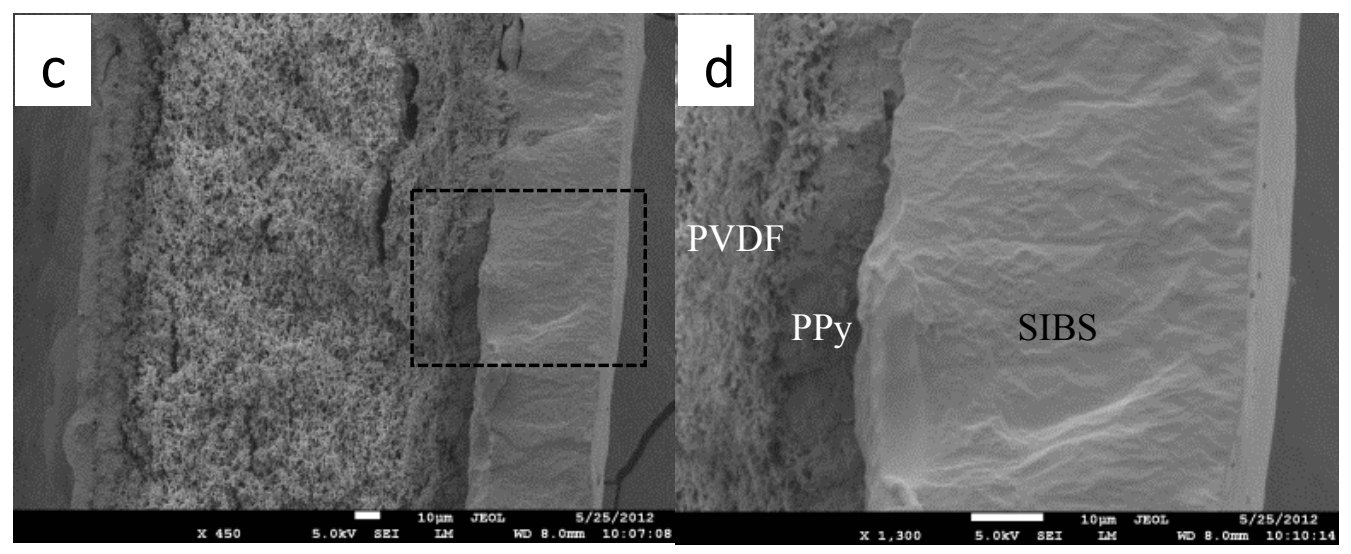

Figure 3. Photographs of an uncoated (a), and a spray coated sample (b). (c, d) Cross section microstructure of a SIBS coated PPy tri-layer actuator. In (c) the SIBS coating was detached from the left hand side of the sample during cryofracturing. Scale bar is $10 \mu \mathrm{m}(\mathrm{c}, \mathrm{d})$.

For each sample the coating thickness and density were determined. The coating density was calculated based on the mass of SIBS deposited on one side of the sample per unit area. Coating thickness was defined as the thickness of coating applied on one side of the sample using a micrometer and the SEM. figure 4 plots the coating thickness as a function of coating density for increasing number of spray applications. The slope of the linear fit provides an estimate of SIBS density (see Supporting Information) as $0.95 \mathrm{mg} \mathrm{mm}^{-3}$, which falls between that of PS (1.05-1.06 mg $\left.\mathrm{mm}^{-3}\right)$ and PIB $\left(0.913 \mathrm{mg} \mathrm{mm}^{-3}\right)$ [23]. 


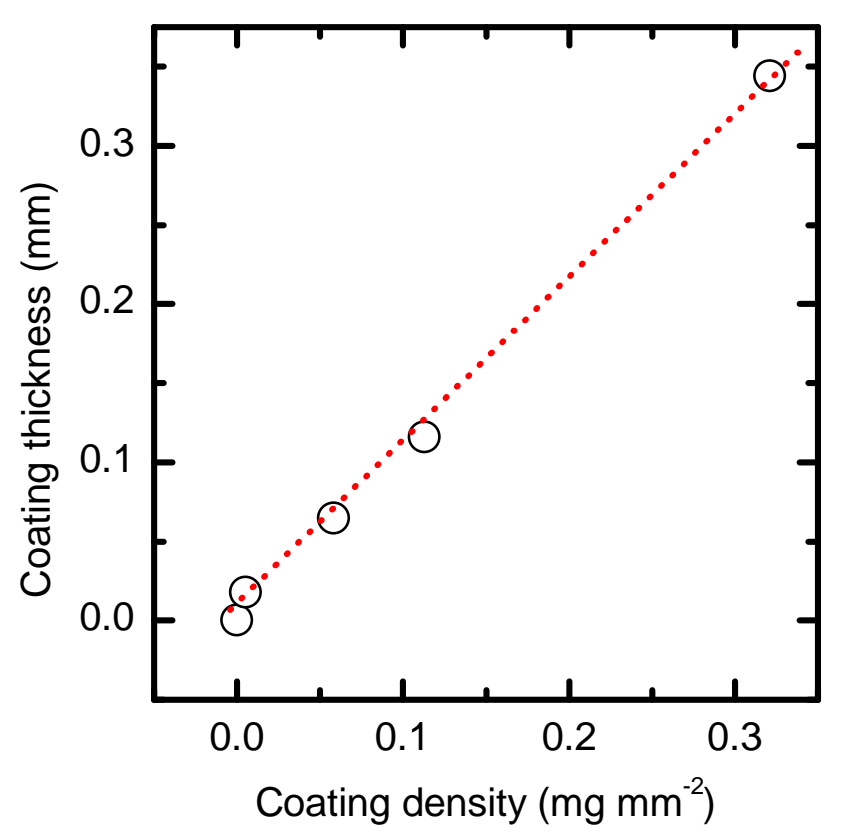

Figure 4. Coating thickness as a function of coating density for increasing number of spray coatings applied.

The effect of the SIBS coating on the operating lifetime of the PPy actuators was investigated by monitoring the tip displacement during voltage cycling. Previous work has shown that tip displacement increases with a higher input voltage [24] and lower frequency [25]. In the present study all samples tested in air were continuously evaluated by applying a square wave potential $(-1$ to +1 $\mathrm{V}, 1 \mathrm{~Hz}$ ) and recording the actual displacement over the course of the experiment (see Supporting Material). The same procedure was also used for the coated actuators tested in water. However, the uncoated samples were unstable in water so that the laser sensor would not remain in focus. These samples were intermediately immersed in and then removed for actuation testing in air under the same condition mentioned above. The displacement was measured by focusing the laser on the same spot each time. Thus, the uncoated samples were immersed in water for one minute, removed from the water and actuated for one minute before being returned to the water.

The retained displacement as a function of actuation cycle for both uncoated and coated actuators operating in air and in water is illustrated in figure 5(a). The retained displacement is the ratio of 
actuator displacement in each cycle to the initial displacement expressed as a percentage. As shown in figure 5(a), the mid-life of actuators at which the displacement dropped by $50 \%$ during the test was 180, 7180, 27000, and 92700 cycles for, respectively, uncoated actuator in water, uncoated actuator in air, coated actuator in water (coating density $0.129 \mathrm{mg} \mathrm{mm}^{-2}$ ), and coated actuator in air (coating density $0.093 \mathrm{mg} \mathrm{mm}^{-2}$ ). The most impressive enhancement in the performance was achieved when spray coated samples were compared with uncoated samples and operating in water. More than 100 times improvement was observed in the number of cycles to reach the half-life. While it takes only a few minutes for an uncoated actuator operating in water to lose $50 \%$ of its initial displacement, a SIBS coated actuator operating in water under the same conditions can operate continuously for more than 7 hours before reaching that point. More interestingly, the overall performance of coated samples actuating in water was superior to the uncoated samples actuating in air.
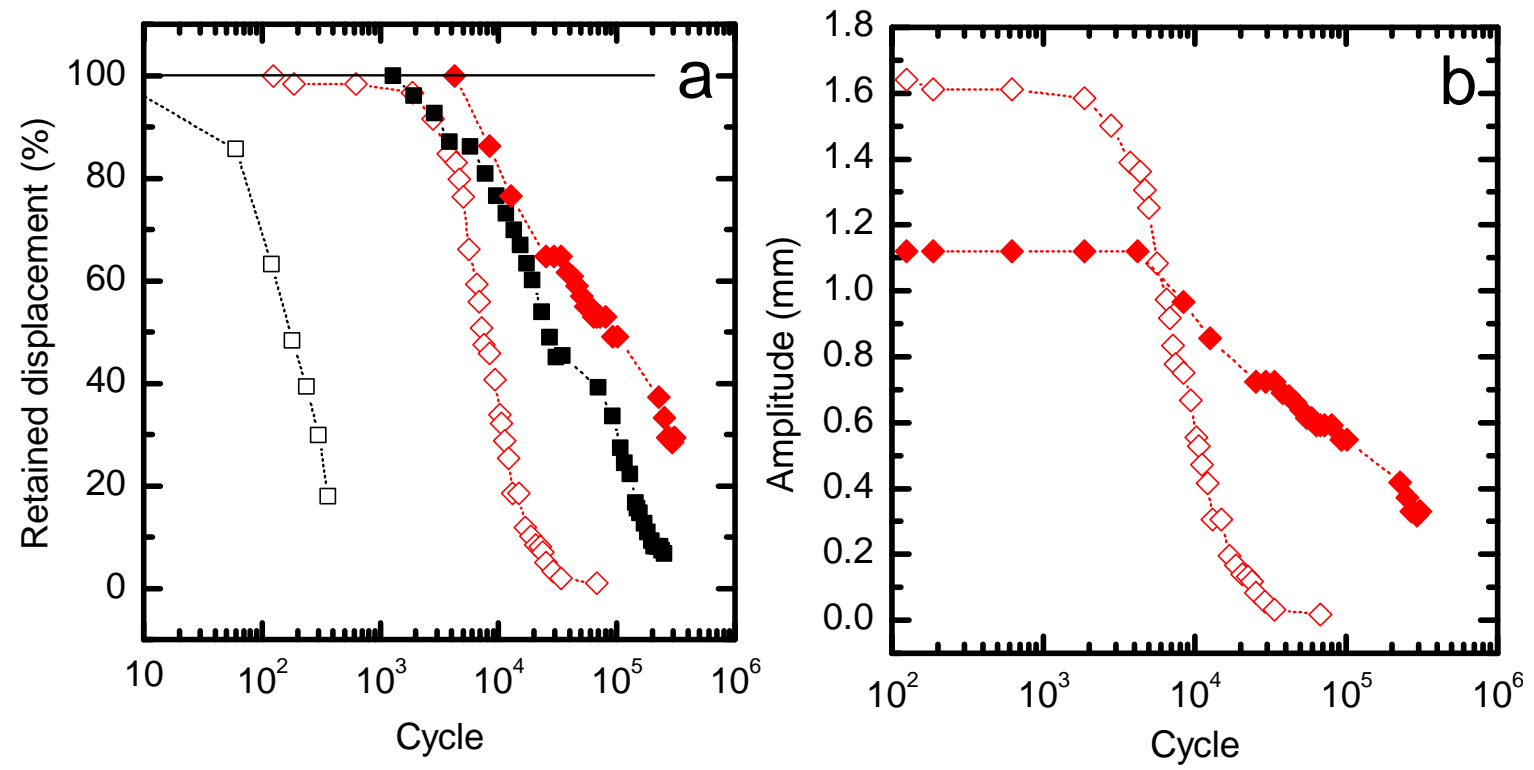

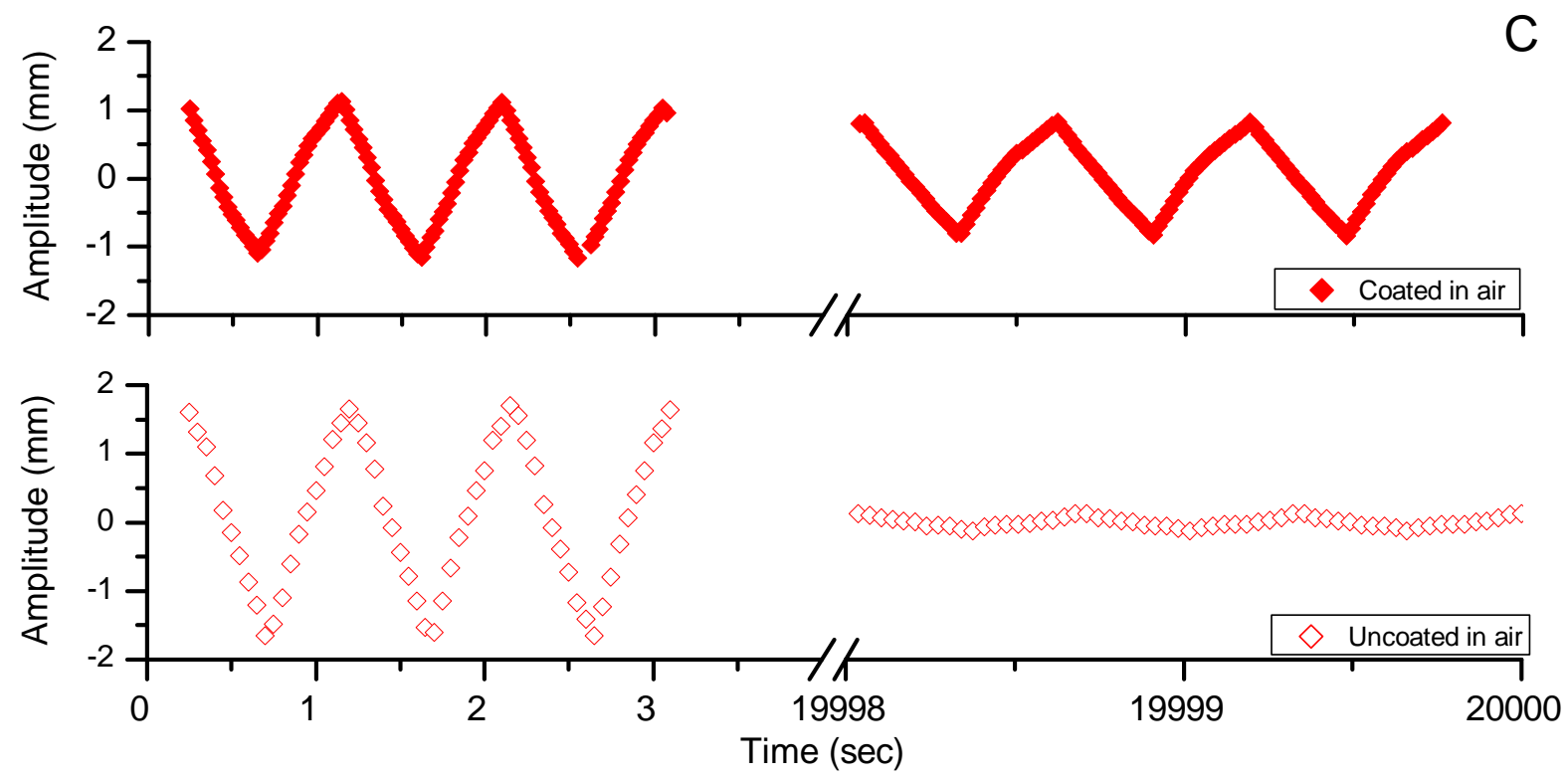

Figure 5. (a) Comparison between performance of coated (filled symbols) and uncoated (open symbols) samples operating in air (diamonds) or in the water (squares). The absolute amplitude of actuation is presented in (b) for samples operating in air. Coating density: $0.129 \mathrm{mg} \mathrm{mm}^{-2}$ (filled squares) and $0.093 \mathrm{mg} \mathrm{mm}^{-2}$ (filled diamonds). (c) Tip displacement in the initial cycles and after $10^{4}$ cycles for coated (filled diamonds) and uncoated (open diamonds) actuators operating in air.

The number of cycles for which no considerable change in displacement amplitude was observed is presented in table 2 for samples with various coating density. The displacement remained at $\sim 100 \%$ of the initial displacement for only 30 cycles for the uncoated actuator in water and only 155 cycles for the uncoated actuator in air. The coated samples could be operated to $4 \times 10^{3}$ cycles in air and over $1 \times 10^{3}$ cycles in water before the displacement began to deteriorate.

Table 2. Number of cycles with no change in actuation displacement.

\begin{tabular}{ccc}
\hline $\begin{array}{c}\text { Coating density } \\
\left(\mathrm{mg} \mathrm{mm}^{-2}\right)\end{array}$ & Air & Water \\
\hline no coating & 155 & $<30$ \\
0.033 & 700 & - \\
0.093 & 4200 & -
\end{tabular}


Of additional interest was the influence of the SIBS coating on the amplitude of actuation. While spray coating significantly improved the operating lifetime of actuators in air and especially in water, the overall actuation amplitude was observed to decrease with increasing coating density. Figure 5(b) and figure 5(c) highlight the effect of coating on the actuation amplitude of bender actuators operating in air. By introducing a layer of coating the initial actuation amplitude decreased from $\sim 1.6 \mathrm{~mm}$ for the uncoated actuator to $\sim 1.1 \mathrm{~mm}$ for the coated sample. However, over a longer period of time the bending amplitude of the coated actuator was larger and remained more consistent compared with the uncoated actuator. After $10^{4}$ cycles, the amplitude of uncoated sample was $\sim 0.55 \mathrm{~mm}$ while the coated sample was actuating with $0.9 \mathrm{~mm}$ amplitude. The measured displacement also decreased with increasing coating thickness as shown in figure 6.

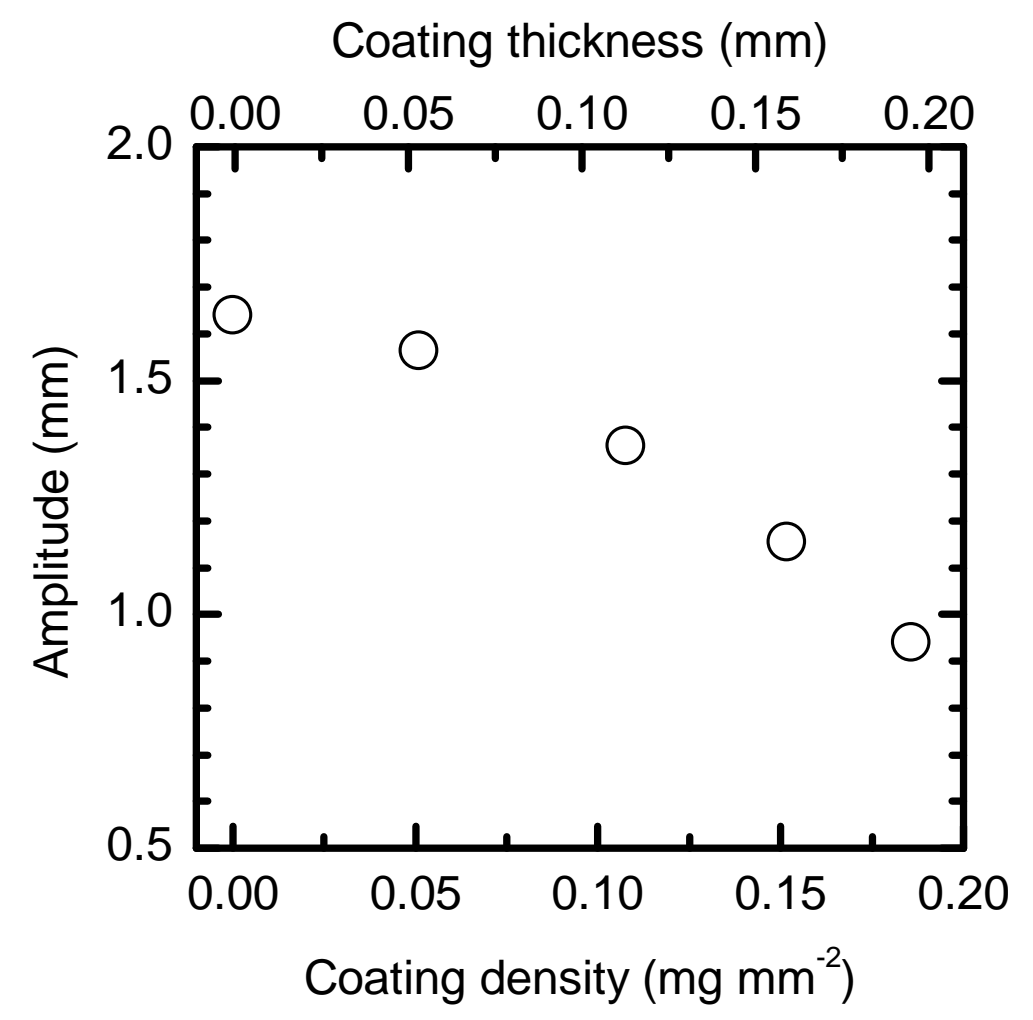


Figure 6. Actuation amplitude at different coating density (coating thickness). Test was carried out in air $(-1$ to $+1 \mathrm{~V}, 1 \mathrm{~Hz})$. Actuator dimension: $29 \mathrm{~mm} \times 5.7 \mathrm{~mm} \times 0.162 \mathrm{~mm}$.

To understand the effect of the SIBS coating on the bending behaviour of tri-layer actuators, it is important to note that during spray coating thickness, mass, apparent modulus and overall flexural stiffness of actuators will be affected. The flexural stiffness of samples was measured by treating the actuators as a cantilever where the damped harmonic oscillator formula is applicable [25-27]:

$$
k=\frac{F}{\delta}=\left(\omega^{2}+\gamma^{2}\right) m
$$

where, $k$ is spring constant (a measure of flexural stiffness), $F$ is applied force, $\delta$ is cantilever deflection, $\omega$ is cantilever oscillation frequency, $\gamma$ is the damping factor, and $m$ is mass of cantilever (increasing with coating). To measure $k$ as a function of coating thickness, actuators with different coating density were manually deflected and then released while their harmonic oscillation was recorded using the laser sensor. The period of oscillation of the cantilever $T_{d}$ was calculated from:

$$
T_{d}=\frac{2 \pi}{\omega}
$$

The damping factor was determined by the amplitude of successive oscillations using:

$$
\text { Amplitude Ratio }=e^{-\gamma T_{d}}
$$

By using equations $1-3, k$ can be expressed as a function of coating density and coating thickness (figure 7), and measurements show that $k$ increases considerably with increasing coating thickness. Hence, the observed decrease in amplitude of actuation as coating thickness increases (figure 6) can be attributed to the increase in the total flexural stiffness of the actuator when a thicker coating was applied. Under the same applied potential the bending force $F$ generated by the actuator is assumed to remain constant. As shown from the first part of equation 1 the deflection of actuator $\delta$ will decrease as $k$ increases. 


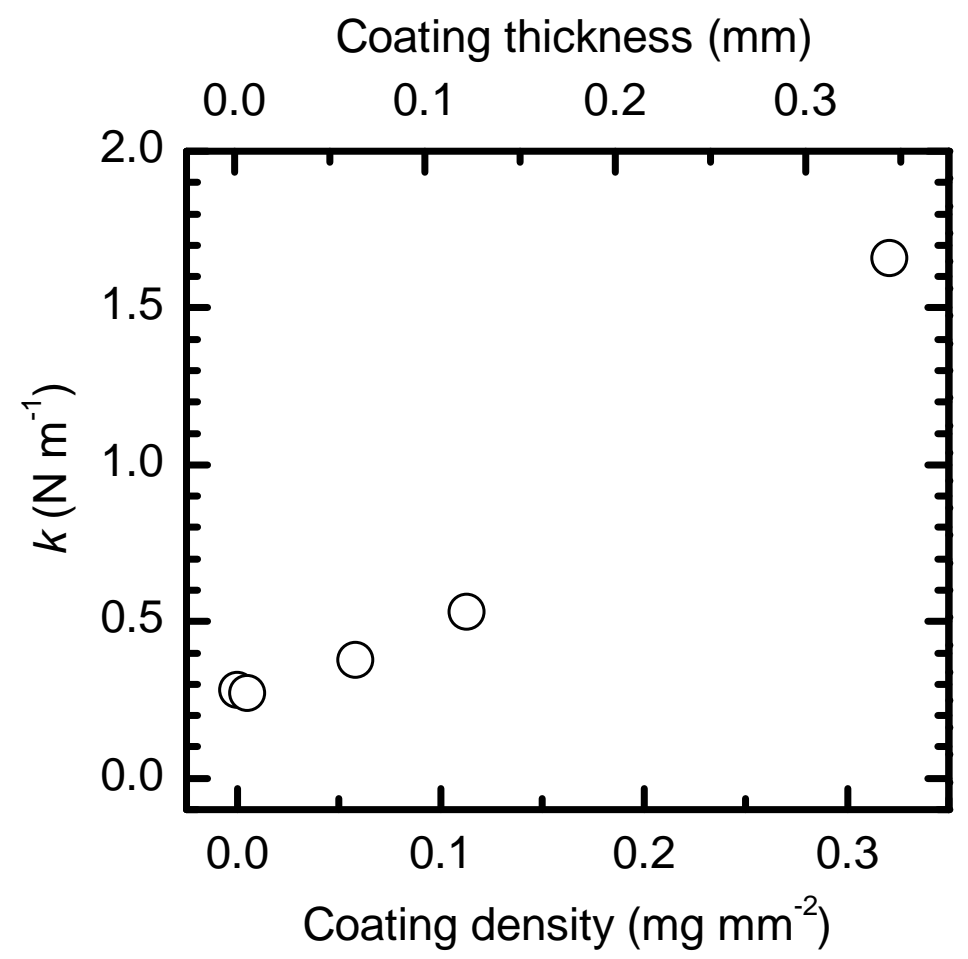

Figure 7. $k$ as a function of coating density (coating thickness).

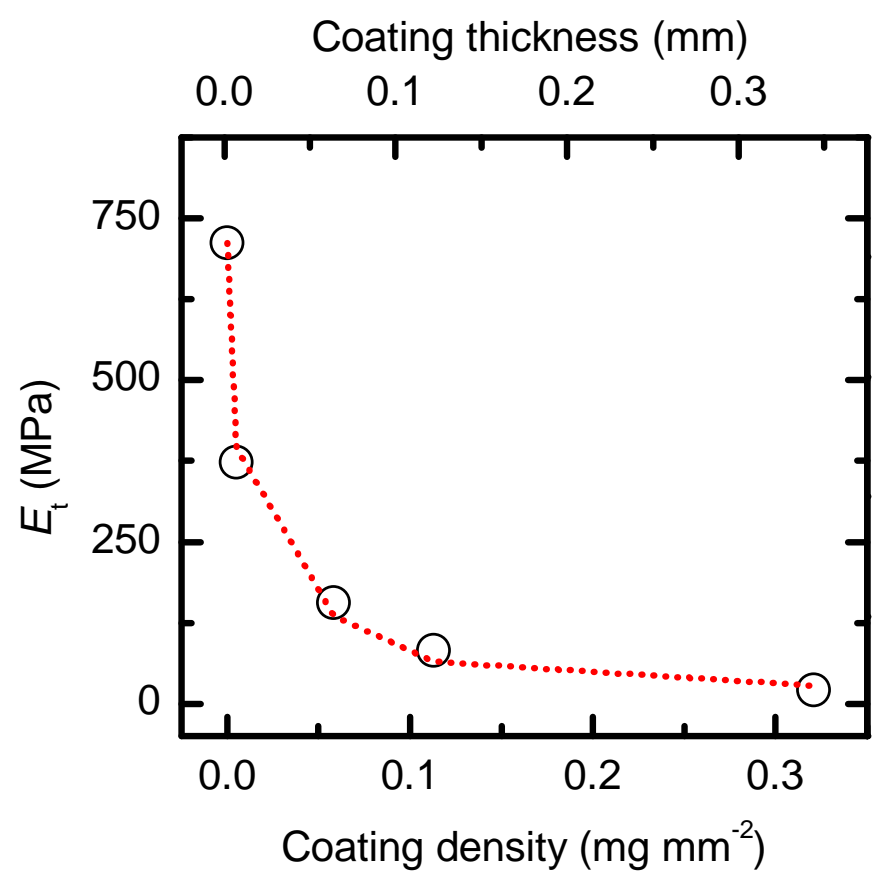

Figure 8. Total apparent modulus of actuators with different coating density (coating thickness). The dotted line represents predicted $\mathrm{E}_{\mathrm{t}}$ based on $E_{\mathrm{SIBS}}=25 \mathrm{MPa}$. 
It is of interest to investigate whether the observed increase in stiffness is dominated by the thickness factor or an enhancement in modulus of coated actuators. The total apparent modulus of coated actuators $E_{t}$ when treated as a cantilever can be related to $k$ using beam mechanics [28]:

$$
E_{t}=\frac{4 l_{t}^{3} k}{w_{t} h_{t}^{3}}
$$

here, $l_{t}, w_{t}$, and $h_{t}$ are the coated actuator total length, width and height. Interestingly, by adding thicker SIBS coatings onto the actuators, $E_{t}$ decreased considerably (figure 8 ). For uncoated actuators, the calculated flexural modulus $(\sim 712 \mathrm{MPa})$ was within the range previously reported in the literature [3]. $E_{t}$ is a combination of PPy bending middle layer and SIBS coatings moduli ( $E_{b}$ and $E_{S I B S}$, respectively). On the other hand, the flexural rigidity of a laminated cantilever made of multi layers of materials can be expressed in the form of flexural rigidity of each element:

$$
E_{t} I_{t}=\sum_{i} E_{i} I_{i}
$$

where $E_{i}$ is modulus and $I_{i}$ is area moment of inertia for each individual element with respect to the neutral axis [20]. A similar approach was successfully used to model uncoated PPy benders [24], but here we treat the PPy tri-layer as if it were a homogeneous material. In the present study, equation 5 can be rewritten for coated actuators as:

$$
\begin{gathered}
E_{t} I_{t}=E_{b} I_{b}+2 E_{S I B S} I_{S I B S} \\
I_{t}=\frac{w_{t} h_{t}^{3}}{12} \\
I_{b}=\frac{w_{b} h_{b}^{3}}{12} \\
I_{S I B S}=\frac{w_{t}\left(h_{t}-h_{b}\right)^{3}}{96}+\frac{w_{t}\left(h_{t}-h_{b}\right)\left(h_{t}+h_{b}\right)^{2}}{32}
\end{gathered}
$$

again, $w$ and $h$ are width and height. Indexes $t$ and $b$ represent total width and height of coated actuators as a whole and those of PPy-PVDF bending middle layer, respectively (figure 9). The 
parallel axis theorem is used to calculate the moment of area of the SIBS layer with respect to the neutral axis. In equations $6, h_{t}$ increases with coating thickness, while $E_{b}$ and $E_{S I B S}$ remain constant. Consequently, the apparent modulus of the coated actuator $\left(E_{t}\right)$ decreases with increasing coating thickness, as presented in figure 8 . By calculating $E_{t}$ from equation 4 and using equations 6 , the Young's modulus of SIBS $E_{\text {SIBS }}$ was calculated to be approximately $25 \mathrm{MPa}$ (dotted line in figure 8 ). Flexural modulus of a cast SIBS film was directly measured using the above resonance technique, and found to be $12 \mathrm{MPa}$, which is in the same order of magnitude as the calculated value. However, it is important to note that although made from the same material, the spray coated SIBS might have a different structure compared to the cast film.

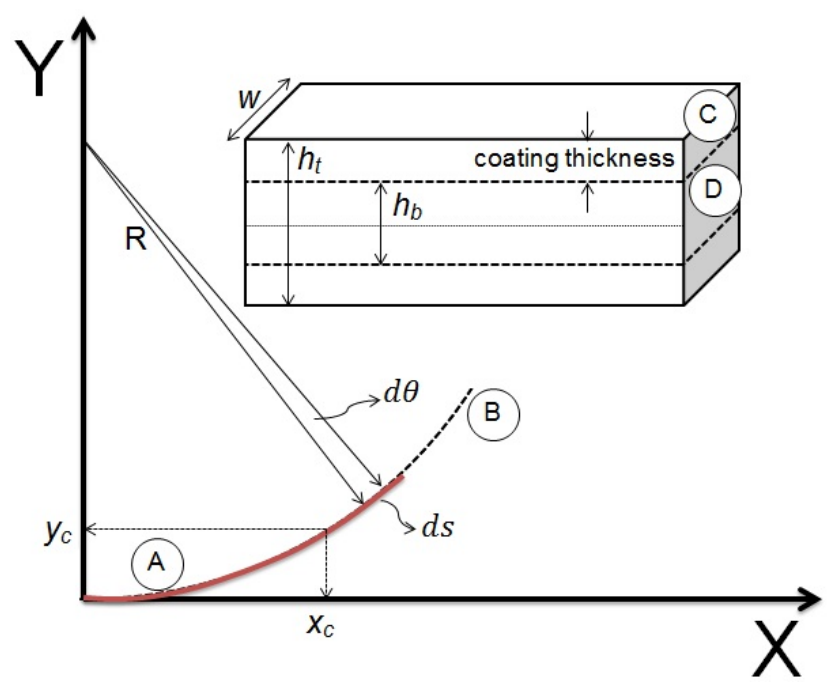

Figure 9. Schematic representation of an actuator (A) in operation. Actuator curvature is part of a circle (B) with radius R. Actuator is modelled as a multi-layer cantilever, made of two outer layers of coating (C), and a middle layer of PPy-PVDF bender (D).

The radius of curvature of bending actuators has been modelled previously (for example see ref. 21). By assuming that this curvature is part of a circle with its centre located on the $\mathrm{Y}$ axis as shown in figure 9 , the coordination of actuator curvature was calculated as a function of coating thickness and 
coating density. Under the steady state condition, the induced bending moment $M$ of the bending actuator correlates with applied voltage, capacitance and the geometry of the system [21]. From beam mechanics bending moment can be expressed as [20]:

$$
M=\frac{d \theta}{d s} \sum_{i} E_{i} I_{i}
$$

here $d \theta / d s$ is beam curvature (figure 9), and can be rearranged into the expression for beam curvature coordinates (see Supporting Information):

$$
\frac{d \theta}{d s}=\frac{\frac{d^{2} y}{d x^{2}}}{1+\left(\frac{d y}{d x}\right)^{2}}
$$

Using equations 6,7 , and 8 actuator displacement $y_{c}$ was calculated for a given horizontal position $x_{c}$, for different coating thickness. (More details on estimating displacement are available in the Supporting Information.) The results were compared with experimentally measured displacements from figure 6 and presented in figure 10. Excellent agreement between the calculated and measured values was obtained.

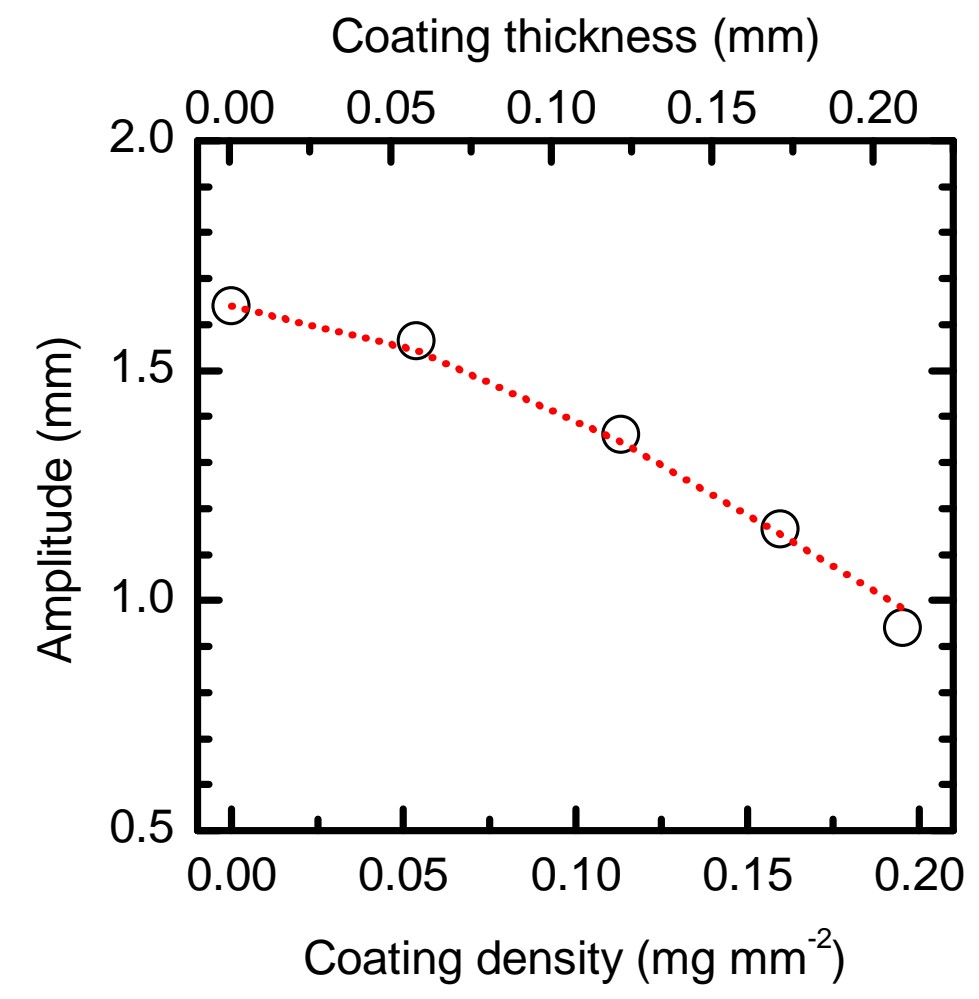


Figure 10. Comparison between experimental data (circles) and the model (dotted line) at different coating thicknesses. Actuator dimension: $29 \mathrm{~mm} \times 5.7 \mathrm{~mm} \times 0.162 \mathrm{~mm}$.

Table 3. Predicted loss in amplitude for various polymer coatings with different modulus. Actuator geometry is the same as in figure 10. Coating thickness is $0.1 \mathrm{~mm}$ in all cases.

\begin{tabular}{ccc}
\hline $\begin{array}{c}\text { Coating } \\
\text { material }\end{array}$ & $\begin{array}{c}\text { Modulus } \\
(\mathrm{MPa})\end{array}$ & $\begin{array}{c}\text { Amplitude loss } \\
(\%)\end{array}$ \\
\hline P-PVC $^{\mathrm{a}}$ & $10[29]$ & 6.7 \\
SIBS & $12-25$ & $7.9-14.6$ \\
EVA $^{\mathrm{b}}$ & $50[30]$ & 25.6 \\
${ }^{\mathrm{PS}}$ & $3000[29]$ & 95.5 \\
\hline${ }^{\text {p }}$ plastisized poly(vinylchloride) ${ }^{\mathrm{b}}$ poly(ethylene vinyl acetate)
\end{tabular}

Since spray coating is a versatile technique for coating a substrate with different polymer materials, the above model can be used to predict the decrease in amplitude of actuators coated with different polymers as a function of their coating thickness. Table 3 lists the percentage loss in amplitude of an actuator coated with 4 specified polymers with a coating thickness of $0.1 \mathrm{~mm}$. Polymers listed in table 3 were chosen as examples of those resistant in propylene carbonate, and covering a wide range of modulus. As expected the modulus of the coating material has a large impact on displacement amplitude.

\section{Conclusions}

Spray coating was demonstrated to be an effective technique for encapsulation of PPy bending actuators. SIBS was used as a biocompatible thermoplastic elastomer with notable resistance against small molecules diffusion to spray coat tri-layer actuators. SIBS coated actuators exhibited a considerable enhanced performance in air and when immersed in water, with more than 100 times improvement in actuator half-life when operating in water. A simple model was derived to predict the change in actuator bending amplitude caused by the coating layer. The encapsulation of PPy actuators 
resulted in extended lifetimes in both aqueous solutions and air which broadening the application of conjugated polymer actuators in biomedical and naval applications.

\section{Acknowledgement}

The authors thank the Australian Research Council for financial support through the Centres of Excellence, Linkage Infrastructure and Fellowship programs and the authors also acknowledge use of the facilities and the assistance of Tony Romeo at the UOW Electron Microscopy Centre.

\section{References}

[1] Smela E 2005 Conjugated polymer actuators for biomedical applications Adv. Mater. 15 481-94.

[2] Immerstrand C, Holmgren-Peterson K, Magnusson K-E, Jager E, Krogh M, Skoglund M, Selbing A, Inganäs O 2002 Conjugated-polymer micro- and milliactuators for biological applications MRS Bulletin 27 461-64.

[3] Madden J D W, Vandesteeg N A, Anquetil P A, Madden P G A, Takshi A, Pytel R Z, Lafontaine S R, Wieringa P A, Hunter I W 2004 Artificial muscle technology: physical principle and naval prospects IEEE J. Ocean. Eng. 29 706-28.

[4] Otero T F, Angulo E, Rodríguez J, Santamaría C 1992 Electrochemomechanical properties from a bilayer: polypyrrole/non-conducting and flexible material - artificial muscle J. Electroanal. Chem. $341369-75$.

[5] Pei Q, Inganas O, Lundstrom I 1993 Bending bilayer strips built from polyaniline electrochemical muscles Smart Mater. Struct. 2 1-6.

[6] Jager E W H, Smela E, Inganäs O 2000 Microfabricating conjugated polymer actuators Science $2901540-45$.

[7] Kaneto K, Kaneko M, Min Y, MacDiarmid A G 1995 "Artificial muscle": electrochemical actuators using polyaniline films Synth. Met. 71 2211-12.

[8] Sansiñena J M, Olazábal V, Otero T F, Polo da Fonseca C N, De Paoli M-A 1997 A solid artificial muscle based on polypyrrole and a solid polymeric electrolyte working in air Chem. Comm. 2217-18.

[9] Baughman R H 1996 Conducting polymer artificial muscles Synth. Met. 78 339-53.

[10] Madden J D, Cush R A, Kanigan T S, Hunter I W 2000 Fast contracting polypyrrole actuators, Synth. Met. 113 185-92. 
[11] Shoa T, Madden J D, Munce N R, Yang V X D 2009 Steerable catheters in: Biomedical Applications of Electroactive Polymer Actuators ed F Carpi, E Smela (John Wiley \& Sons: Sussex) $229-46$.

[12] Mazzoldi A, De Rossi D 2000 Conductive-polymer-based structure for a steerable catheter Proc. SPIE 3987 273-80.

[13] Fay C, Lau K-T, Beirne S, Conaire C Ó, McGuinness K, Corcoran B, O’Connor N E, Diamond D, McGovern S, Coleman G, Shepherd R, Alici G, Spinks G, Wallace G 2010 Wireless aquatic navigator for detection and analysis (WANDA) Sens. Actuators B 150 425-35.

[14] Zhou D, Wallace G G, Spinks G M, Liu L, Cowan R, Saunders E, Newbold C 2003 Actuators for the cochlear implant Synth. Met. 135-136 39-40.

[15] Lu W, Fadeev A G, Qi B, Smela E, Mattes B R, Ding J, Spinks G M, Mazurkiewicz J, Zhou D, Wallace G G, MacFarlane D R, Forsyth S A, Forsyth M 2002 Use of ionic liquids for $\pi$-conjugated polymer electrochemical devices Science 297 983-87.

[16] Ding J, Liu L, Spinks G M, Zhou D, Wallace G G, Gillespie J 2003 High performance conducting polymer actuators utilising a tubular geometry and helical wire interconnects Synth. Met. 138 391-98.

[17] Zhou D, Spinks G M, Wallace G G, Tiyapiboonchaiya C, MacFarlane D R, Forsyth M, Sun J 2003 Solid state actuators based on polypyrrole and polymer-in-ionic liquid electrolytes Electrochim. Acta 48 2355-59.

[18] Madden J D, Cush R A, Kanigan T S, Brenan C J, Hunter I W 1999 Encapsulated polypyrrole actuators Synth. Met. 105 61-64.

[19] McGovern S, Alici G, Truong V-T, Spinks G 2009 Finding NEMO (novel electromaterial muscle oscillator): a polypyrrole powered robotic fish with real-time wireless speed and directional control Smart Mater. Struct. 18095009.

[20] McGovern S T, Abbot M, Emery R, Alici G, Truong V-T, Spinks G M, Wallace G G 2010 Evaluation of thrust force generated for a robotic fish propelled with polypyrrole actuators Polym. Int. $59357-64$.

[21] Pinchuk L, Wilson G J, Barry J J, Schoephoerster R T, Parel J-M, Kennedy J P 2008 Medical applications of poly(styrene-block-isobutylene-block-styrene) (“SIBS”) Biomaterials 29 448-60.

[22] Boyd R H, Krishna Pant P V 1991 Molecular packing and diffusion in polyisobutylene Macromolecules 24 6325-31.

[23] Van Krevelen D W, Hoftyzer P J 1969 Prediction of polymer density J. Appl. Polym. Sci. 13 $871-81$.

[24] Alici G, Mui B, Cook C 2006 Bending modelling and its experimental verification for conducting polymer actuators dedicated to manipulation applications Sens. Actuators A 126 396-404.

[25] Wu Y, Alici G, Spinks G M, Wallace G G 2006 Fast trilayer polypyrrole bending actuators for high speed applications Synth. Met. 156 1017-22. 
[26] Steidel R F 1989 An Introduction to Mechanical Vibrations (John Wiley \& Sons: New York).

[27] John S W, Alici G, Cook C D 2008 Validation of resonant frequency model for polypyrrole trilayer actuators IEEE-ASME Trans. Mechatron. 13 401-9.

[28] Gere J M 2001 Mechanics of Materials (Brooks/Cole: London).

[29] Crawford R J 1998 Plastics Engineering (Butterworth-Heinemann: Oxford).

[30] Modern Plastics Encyclopedia (McGraw-Hill) B158-B216. 